\title{
What drives inappropriate use of antibiotics? A mixed methods study from Bahawalpur, Pakistan
}

This article was published in the following Dove Medical Press journal: Infection and Drug Resistance

\section{Muhammad Atif ${ }^{\prime}$ \\ Saima Asghar ${ }^{1}$ \\ Irem Mushtaq ${ }^{2}$ \\ Iram Malik' \\ Anum Amin' \\ Zaheer-Ud-Din Babar ${ }^{3}$ \\ Shane Scahill ${ }^{4}$}

'Department of Pharmacy, The Islamia University of Bahawalpur, Bahawalpur, Pakistan; ${ }^{2}$ Department of Education, The Islamia University of Bahawalpur, Bahawalpur, Pakistan; ${ }^{3}$ Department of Pharmacy, University of Huddersfield, Huddersfield, UK; ${ }^{4}$ School of Management, Massey Business School, Massey University, Auckland, New Zealand
Correspondence: Muhammad Atif Department of Pharmacy, The Islamia University of Bahawalpur, Railway Road, 63100, Bahawalpur, Pakistan

Tel +92 32I 68I 1084

Email pharmacist_atif@yahoo.com
Purpose: This study investigates the knowledge, attitudes and practices of the general public regarding the use of antibiotics in community pharmacy, in Pakistan.

Methods: This is a mixed method study where data were collected through a validated questionnaire and semi-structured interviews. Convenience sampling techniques were used to recruit participants from the general public of Bahawalpur, Pakistan who visited pharmacies to purchase antibiotics between 1 June 2018 and 31 July 2018. Descriptive statistics and regression analyses were used to tabulate the results of quantitative data while inductive thematic analysis was used to identify themes and draw conclusions from the qualitative data.

Results: Over $60 \%$ of the 400 survey participants ( $n=246 ; 61.5 \%)$ had a moderate level of antibiotic knowledge; however, attitudes regarding antibiotics use were poor in half the sample $(n=201 ; 50.3 \%)$. More than half $(n=226 ; 56.6 \%)$ of the respondents stated that antibiotics could cure all types of infections. Just under one third $(n=129 ; 32.3 \%)$ of respondents obtained the appropriate dosage regimen while the majority did not complete the course ( $n=369 ; 92.3 \%)$; stopping when they felt better. Inductive thematic analysis yielded four themes, 10 subthemes and 27 categories. Two subthemes were related to knowledge, one to attitude, three to practices and four subthemes were related to suggestions to improve the healthcare system. Inappropriate antibiotic practices included: lack of consultation with healthcare professionals, purchase of antibiotics without prescription or refilling of previous prescription, use of home supply of antibiotics, sharing of antibiotics with others, improper dosage regimens and early cessation of antibiotic therapy.

Conclusion: Level of education, low health literacy, high consultation fees of private practitioners, inadequate health facilities in government hospitals and patient overload, busy schedules of people, poor healthcare infrastructure in rural areas and unrestricted supply of antibiotics were key factors associated with inappropriate use of antibiotics in Pakistan.

Keywords: antibiotic resistance, general public, knowledge, health literacy, self-medication

\section{Introduction}

Medicines are the single most common medical intervention and antibiotics have modernized healthcare since their discovery in $1928 .{ }^{1}$ The impact of antibiotics in terms of morbidity and mortality from bacterial infection has been monumental, making them essential to modern medicine. ${ }^{1}$ Infections and life-saving interventions such as chemotherapy, organ transplants and surgery rely on effective antibiotics. ${ }^{2}$ However, the flipside of availability is the inappropriate use, which include incorrect dose, inadequate duration, inappropriate frequency and indication, overuse of broad-spectrum antibiotics and incomplete courses of therapy which are global issues that are escalating at an alarming 
rate..$^{3-5}$ It is estimated that up to $50 \%$ of all medicines including antibiotics are prescribed, sold or dispensed inappropriately; on top of this, half of patients are not taking these correctly. ${ }^{6,7}$ Antibiotic resistance is a direct consequence of inappropriate antibiotic use and a major public health problem worldwide. ${ }^{6}$ This results in long lasting infections, prolonged hospital stay, higher treatment costs, limited treatment options and increased mortality rates due to "hard to kill" infectious diseases. ${ }^{5,8-11}$ It is estimated that by 2050 , as a consequence of increases in drug resistant infections, 10 million lives per year and 100 trillion US dollars (USD) of economic output will be put at risk. ${ }^{12,13}$

Many factors play roles in the inappropriate use of antibiotics, for example a lack of patient health literacy, unsupervised self-medication, unnecessary and sub-optimal consumption, availability of over-the-counter (OTC) antibiotics and antibiotics being sold without a prescription. ${ }^{4,14-17}$ Although the inappropriate use of antibiotics is prevalent globally, developing countries are most affected due to higher infection rates and limited resources. ${ }^{18,19}$ This study is located in Pakistan which is a developing country with a compromised healthcare infrastructure where antibiotics can be bought over the counter. ${ }^{20,21}$ An inadequate financial situation, low literacy rate and suboptimal healthcare facilities mean that the usual monitoring and treatment of health care might not be in place, antibiotic use included. ${ }^{20}$ Pakistan is ranked the third highest country for antibiotic consumption among low-income countries and antibiotic consumption increased from 0.8 to 1.3 billion defined daily dose (DDDs) (65\% increase) between 2000 and 2015. ${ }^{22}$ There is a small number of studies which report high prescribing rates of antibiotics in Pakistan ${ }^{15,18}$ as well as sub-optimal use. ${ }^{23,24}$ There is a Pakistani study reporting inappropriate use of antibiotics to be common, leading to life-threatening resistance issues in the country. ${ }^{25}$

The inappropriate use of antibiotics is strongly associated with a lack of public awareness and adequate knowledge of antibiotics and their use. ${ }^{26}$ Better awareness and knowledge of antibiotics among the general public and having positive attitudes and practices towards the appropriate use of these medicines play a significant role in reducing consumption. ${ }^{5}$ As such there is a need to understand the knowledge, attitudes and practices of the general public regarding antibiotic use and to report the factors that drive the behavior to use antibiotics inappropriately. This is particularly the case in countries like Pakistan where access to antibiotics is relatively open. Part of this is to understand how health care consumers decide that the medicine they are opting to buy and use, best suits their needs. The aim of this study is to investigate the Pakistani public knowledge, attitudes, and practices regarding antibiotic use, upon visiting a pharmacy.

\section{Methods}

\section{Study design and setting}

A mixed method study design was used where data were collected from two pharmacies (Pharmacy X and Pharmacy $\mathrm{Y}$ ), which were under pharmacist supervision in Bahawalpur, Punjab, Pakistan. The population of this city is 3.67 million. ${ }^{27}$ Using a convenience sampling technique, all eligible patients and caregivers (age $\geq 18$ years and visiting the pharmacies to purchase antibiotics with or without a prescription during 1 June to 31 July 2018) were invited to participate in the study. Consenting participants completed the questionnaire (quantitative part) designed to achieve the study objectives. Those completing the questionnaire were also invited to participate in a semi-structured interview until numbers reached the point of data saturation.

\section{Sample size and sampling method}

For the quantitative component of the study, the sample size was determined by using the Raosoft $\mathrm{ft}^{\mathrm{TM}}$ sample size calculator with $95 \%$ CI, 5\% margin of error, and the assumption of an $80 \%$ adherence rate. This generated a sample size requirement of $385 .{ }^{28}$ Assuming attrition rate of $20 \%$ and presence of outliers, a sample of 462 respondents was needed. For the qualitative component, respondents who completed the questionnaire were invited to participate in semi-structured interviews. ${ }^{29}$ The first participants in the quantitative study were eligible for the qualitative part until the point of full data saturation was reached. Data collection was concurrent whereby consented respondents were first asked to complete a questionnaire (quantitative) followed by a semi-structured interview (qualitative).

\section{Survey instruments and data collection Quantitative component}

A validated questionnaire adapted from earlier studies was used to collect the data. ${ }^{4,5}$ The questionnaire was modified through feedback to make the questions suitable for use among the selected population. Forward- and back-translation techniques were used for cross-cultural adaptation of the questionnaire. ${ }^{30,31}$ Two professional translators were involved in the procedure. Pilot testing was performed to ensure the validity of adapted questionnaire. It consisted of four parts. Part 1 contained 9 questions related to demographics of the respondents, while part 2 consisted of 12 questions to assess the knowledge of antibiotics among respondents. Part 3 (8 statements) assessed the general public's attitudes toward antibiotic use and part 4 (9 statements) investigated the practices of antibiotic use (please refer to Table S1). For parts 2 and 3 a five-point Likert scale (strongly agree, agree, uncertain, disagree and strongly disagree) was used. 


\section{Qualitative component}

In-depth interviews were conducted and data were recorded through note taking and tape recording during the interviews. The interview schema was generated through formulating questions that answer the research problem and by addressing gaps in the literature. The interview schema contained 15 questions (with further sub-questions) and is outlined in Supplementary material Table S2. Pilot interviews were undertaken to perform a trial the interview protocol and ensure face validity, uniformity and understandability.

All interviews were conducted in Urdu (national language of Pakistan) at a place and time comfortable and convenient to the interviewees (eg, pharmacist's desk or interviewee work place).

\section{Data analyses Quantitative component}

Data were entered and verified by using EpiData version 3.1 and analyzed by Statistical Package for Social Sciences program (SPSS Statistics for Windows, version 20, IBM Corp., Armonk, NY, USA). A scoring system was used to assess the knowledge and attitude of the respondents. A score of 1 was given for each correct answer and 0 if the answer was wrong or uncertain. The knowledge score was categorized into poor $(0-5 / 15)$, moderate $(6-10 / 15)$ and good (11-15/15) while the attitudes score was divided into poor ( $0-3 / 8)$, moderate $(4-6 / 8)$ and good $(7-8 / 8)$. The overall practices of antibiotic use were determined by "yes" or "no" responses. Cronbach alpha's were used to demonstrate the internal consistency and reliability of the scale.

Simple linear regression was used to identify the factors affecting the general public's knowledge and attitude about antibiotic use. Multiple linear regression was applied to statistically significant variables of the univariate analysis to segregate the independent factors. Beta, standard error and $P$-value were reported for each predictor. Pseudo $R^{2}$ value was included to provide information about the percentage of variance explained by the model. A $P$-value of $\leq 0.05$ was determined to be statistically significant. ${ }^{32}$

\section{Qualitative component}

General inductive thematic analysis was used to analyze the data and draw conclusions from the evolving themes. ${ }^{33}$ The audio recordings were carefully listened to and the noted observations were read by the research team for each interview. Interviews were transcribed verbatim from the audio recordings. Transcribed data were translated from the local Urdu language to English. Meaningful data were extracted and relevant codes were assigned to them. The coded data were then reduced and organized to draw final themes and subthemes from categories. The emergent themes and conclusions were defended through discussion at regular research meetings to confirm they reflect the aims of the study.

\section{Ethics statement}

The ethical code of the Declaration of Helsinki guided the study at every step. Ethical approval was obtained through the Pharmacy Research Ethics Committee (PREC) at the Islamia University Bahawalpur (Reference: 41/S-2018-/PREC, dated 31 May 2018). The objectives of the study were explained to the respondents before the data collection process began. Written informed consent was gained after explaining the participant information sheet and the study objectives to them. Confidentiality was assured and they were given the right to refuse to participate in the study or withdraw from the study without any further questions or implications.

\section{Results \\ Quantitative component}

A total of 462 respondents visiting the two pharmacies for the purchase of antibiotics with or without prescription were approached and of this 400 respondents agreed to participate, resulting in a response rate of $86.6 \%$. Demographic information about the non-responders is provided in Supplementary material Table S3. Patient characteristics (see Table 1) demonstrate that just over half $(\mathrm{n}=220 ; 55 \%)$ were male, the remainder being female ( $\mathrm{n}=180 ; 45 \%)$. Close to half of the respondents $(n=214 ; 53.5 \%)$ were 30 years of age or younger. Most of the respondents $(n=320 ; 80 \%)$ lived in urban areas. Under half of the 400 participants $(n=166 ; 41.5 \%)$ could not recall the number of courses of antibiotics they had used per year.

\section{Knowledge of antibiotics}

The overall mean score of antibiotic knowledge was 7.07 $(\mathrm{SD}=2.2)$ out of the maximum score of 15. A total of 246 $(61.5 \%)$ respondents showed a moderate level of knowledge about antibiotics while 48 (12\%) respondents demonstrated poor knowledge regarding antibiotics (Table 2). A detailed description of knowledge questions and their responses is provided in Supplementary material Table S4.

After adjusting the predictors of antibiotic knowledge in univariate analysis (illiterate, primary education, university education and urban residency) (for univariate analysis, please refer to Supplementary material Table S5), the factors which remained significant in multiple linear regression analysis were illiteracy and primary education (Table 3 ). Definitions of university education and urban residency are provided in Supplementary material Table S6. 
Table I Demographic characteristics of the respondents

\begin{tabular}{|c|c|}
\hline Variables & $\begin{array}{l}\text { Respondents } \\
\text { n (\%) }\end{array}$ \\
\hline \multicolumn{2}{|c|}{ Age, years (mean age $=34.3 \pm 13$ ) } \\
\hline $18-30$ & $214(53.5)$ \\
\hline $31-40$ & $76(19)$ \\
\hline $4 I-50$ & $60(15)$ \\
\hline $51-60$ & $30(7.5)$ \\
\hline$>60$ & $20(5)$ \\
\hline \multicolumn{2}{|l|}{ Education level } \\
\hline Illiterate & $5 \mathrm{I}(12.8)$ \\
\hline Primary & $78(19.5)$ \\
\hline Secondary & $157(39.3)$ \\
\hline University & II4 (28.5) \\
\hline \multicolumn{2}{|l|}{ Gender } \\
\hline Male & $220(55)$ \\
\hline Female & $180(45)$ \\
\hline \multicolumn{2}{|c|}{ Monthly family income (Pakistan Rupees) } \\
\hline$\leq 20,000$ & $159(39.8)$ \\
\hline $21,000-30,000$ & $83(20.8)$ \\
\hline $31,000-40,000$ & 79 (19.8) \\
\hline $41,000-50,000$ & $43(10.8)$ \\
\hline$>50,000$ & $36(9)$ \\
\hline \multicolumn{2}{|l|}{ Residency } \\
\hline Rural & $80(20)$ \\
\hline Urban & $320(80)$ \\
\hline \multicolumn{2}{|c|}{ Work in health sector } \\
\hline Yes & $46(11.5)$ \\
\hline No & $354(88.5)$ \\
\hline \multicolumn{2}{|c|}{ Purchase of antibiotics } \\
\hline With prescription & $28 I(70.3)$ \\
\hline Without prescription & $119(29.8)$ \\
\hline \multicolumn{2}{|c|}{ Range of courses of antibiotics per year } \\
\hline Do not use & $61(15.3)$ \\
\hline $1-3$ & $99(24.8)$ \\
\hline $4-6$ & $50(12.5)$ \\
\hline$>6$ & $24(6)$ \\
\hline Do not know & $166(4 \mid .5)$ \\
\hline
\end{tabular}

Table 2 Level of knowledge among study participants

\begin{tabular}{|l|l|}
\hline Knowledge level & n (\%) \\
\hline Good & $106(26.5)$ \\
\hline Moderate & $246(61.5)$ \\
\hline Poor & $48(12)$ \\
\hline
\end{tabular}

Note: Scoring assumptions: poor (0-5/15), moderate (6-10/15), good (1I-15/15).

Table 3 Predictors of antibiotic knowledge: multiple linear regression analysis

\begin{tabular}{|l|l|l|l|}
\hline Variables & Beta & SE & $P$-value \\
\hline Illiterate & -0.153 & 0.030 & $\mathbf{0 . 0 0 7}$ \\
\hline Primary education & -0.109 & 0.024 & $\mathbf{0 . 0 4 4}$ \\
\hline University education & 0.066 & 0.021 & 0.224 \\
\hline Urban residency & 0.056 & 0.024 & 0.300 \\
\hline
\end{tabular}

Note: Model summary: $R^{2}=0.048, P<0.0005$. $P$-value of $<0.05$ was determined to be statistically significant.

\section{Attitudes toward antibiotic use}

The overall mean score of attitude towards antibiotic use was $3.47(\mathrm{SD}=1.5)$ out of the maximum score of 8 . About half of the respondents $(n=201,50.3 \%)$ showed a poor attitude regarding antibiotic use while $192(48 \%)$ study participants had moderate attitudes. Only $7(1.8 \%)$ respondents had good attitudes regarding antibiotic use (Table 4). A detailed description of the attitude questions and their responses is provided in Supplementary material Table S7.

After adjusting the predictors of attitude in the univariate analysis (illiterate, university education, male gender and antibiotic purchase without prescription and knowledge of antibiotics) (for univariate analysis, please refer to Supplementary material Table S8), the factors which remained significant in the multiple linear regression analysis were male gender, purchase of antibiotics without prescription and knowledge scores (Table 5).

\section{Practices of antibiotic use}

Nearly $70 \%(n=278,69.5 \%)$ of respondents believed they used antibiotics appropriate to their clinical needs. In just over two-thirds ( $\mathrm{n}=271,67.8 \%$ ) of respondents, antibiotic use was inappropriate. Dosage form and route of administration was appropriate in the majority $(\mathrm{n}=343,85.8 \%)$. Over $70 \%$ $(n=268,71.5 \%)$ of respondents did not ask pharmacists about side effects associated with antibiotics. The majority of respondents $(n=369 ; 92.3 \%$ ) stopped taking the antibiotics when they felt better, even if they hadn't completed the course. Only 80 (20\%) respondents discarded the leftover antibiotics whereas 322 (80.5\%) participants kept these for future use (Table 6). Most interestingly, over half of the respondents ( $n=201,52.5 \%$ ) would give the leftover antibiotics to someone else who is sick.

Table 4 Attitude toward antibiotic use

\begin{tabular}{|l|l|}
\hline Attitude & $\mathbf{n ~ ( \% )}$ \\
\hline Good & $7(1.8)$ \\
\hline Moderate & $192(48)$ \\
\hline Poor & $201(50.3)$ \\
\hline
\end{tabular}

Note: Scoring assumptions: poor (0-3/8), moderate (4-6/8), good (7-8/8).

Table 5 Predictors of attitude about antibiotic use: multiple linear regression analysis

\begin{tabular}{|l|l|l|l|}
\hline Variables & Beta & SE & P-value \\
\hline Illiterate & -0.031 & 0.232 & 0.534 \\
\hline University education & 0.084 & 0.169 & 0.089 \\
\hline Male & 0.097 & 0.148 & $\mathbf{0 . 0 4 2}$ \\
\hline $\begin{array}{l}\text { Purchase of antibiotics } \\
\text { without prescription }\end{array}$ & -0.182 & 0.163 & $<\mathbf{0 . 0 0 0 5}$ \\
\hline Knowledge score $^{\mathrm{a}}$ & 0.212 & 0.033 & $<\mathbf{0 . 0 0 0 5}$ \\
\hline
\end{tabular}

Note: ${ }^{a}$ Denotes continuous variable; model summary: $R^{2}=0.118, P<0.0005$. A $P$-value of $<0.05$ was determined to be statistically significant. 


\section{Qualitative component}

A total of 16 in-depth interviews were conducted. Interview duration ranged from 26 to 42 minutes with a mean duration of 34 minutes. Among the participants, 13 were male and 3 were female. The age of the respondents ranged from 22 to 66 years. Participants' characteristics and interview duration are provided in Supplementary material S9. Inductive thematic analysis of the data yielded 4 themes, 10 subthemes and 27 categories. The emergent themes, subthemes and categories are outlined in Table 7.

\section{Theme I: knowledge}

\section{General knowledge about antibiotics}

Knowledge of the general public presenting at two pharmacies about the term "antibiotic" was satisfactory. All of the respondents had heard the term "antibiotic" and most of them defined the term correctly.

Yes, I heard. In infections these are given to kill the germs (Respondent L)

However, respondents were unaware of when to use the antibiotics. The majority were unable to distinguish between bacterial and viral infections. According to their perceptions, antibiotics can be used in all diseases.

These are used for the treatment of any disease (Respondent B)

No disease is there in which antibiotics are not given, in fever, flu, cough or whatever the disease. Without anti- biotic, does not go. These are also used in hepatitis etc.

(Respondent M)

\section{Antibiotic resistance}

Knowledge about antibiotic resistance was unsatisfactory among the general population. Twelve of the 16 respondents had not heard the term "antibiotic resistance". After explaining the term (Supplementary material S10), they responded that they knew this phenomenon to some extent. Participants also explained that many antibiotics had lost their effectiveness.

No, the term is new for me. I heard it for the 1 st time (Respondent $\mathrm{H}$ )

...I heard that medicines are not working... (Respondent J)

Participants did not know the exact reasons for antibiotic resistance. The majority of them were of the opinion that by using more antibiotics, resistance occurs.

By taking too much antibiotics it occurs. When people take too much medicine, body stops to accept it... (Respondent C)

One respondent said that medicines are not of good quality and low quality medicines lead to antibiotic resistance.

May be due to the reason that medicines are of low quality now. These are fake; their effect is present but less (Respondent B)

Table 6 Questions targeting consumer practices

\begin{tabular}{|c|c|c|}
\hline Statement & Yes & No \\
\hline Appropriateness ${ }^{\mathrm{a}}$ of anti-infective agent & $278(69.5)$ & $122(30.5)$ \\
\hline Proper dosage regimen ${ }^{\mathrm{b}}$ of antibiotics & $129(32.3)$ & $27 \mid(67.8)$ \\
\hline Proper dosage form and route of administration & $343(85.8)$ & $57(14.3)$ \\
\hline Ask about side effects from pharmacist at pharmacy & II4 (28.5) & $286(71.5)$ \\
\hline \multicolumn{3}{|l|}{ After taking 2-3 doses you start feeling better. } \\
\hline a) Do you stop taking the antibiotics? & $369(92.3)$ & $31(7.8)$ \\
\hline b) Do you save the remaining antibiotics for the next time you get sick? & $322(80.5)$ & $78(19.5)$ \\
\hline c) Do you discard the remaining antibiotics? & $80(20)$ & $320(80)$ \\
\hline d) Do you give the leftover antibiotics to someone else who is sick? & $210(52.5)$ & $190(47.5)$ \\
\hline \multicolumn{3}{|l|}{ You take antibiotics with } \\
\hline a) Water & $267(66.8)$ & $133(33.2)$ \\
\hline b) Juice & $6(1.5)$ & $394(98.5)$ \\
\hline c) Milk & $127(3.8)$ & $273(96.2)$ \\
\hline \multicolumn{3}{|l|}{ You take antibiotics } \\
\hline a) Before meals & 74 (18.5) & $326(81.5)$ \\
\hline b) After meals & $326(81.5)$ & 74 (18.5) \\
\hline Check the expiry date & $131(32.8)$ & $269(67.3)$ \\
\hline
\end{tabular}

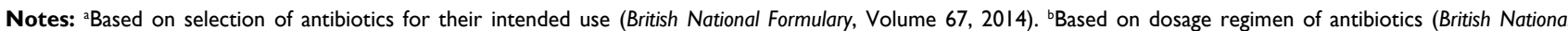
Formulary, Volume 67, 2014).45 
Table 7 Themes, subthemes, and categories

\begin{tabular}{|c|c|c|}
\hline Themes & Subthemes & Categories \\
\hline \multirow[t]{2}{*}{ Knowledge } & $\begin{array}{l}\text { General } \\
\text { knowledge about } \\
\text { antibiotics }\end{array}$ & $\begin{array}{l}\text { Familiar with the term antibiotics. } \\
\text { Low knowledge about the medical conditions to be treated with antibiotics. } \\
\text { Unable to differentiate bacterial and viral infections. }\end{array}$ \\
\hline & $\begin{array}{l}\text { Antibiotic } \\
\text { resistance }\end{array}$ & $\begin{array}{l}\text { Not familiar with the term. } \\
\text { Inadequate knowledge about antibiotic resistance. } \\
\text { Causes of resistance were not completely known. }\end{array}$ \\
\hline Attitude & $\begin{array}{l}\text { Attitude regarding } \\
\text { use of antibiotics }\end{array}$ & $\begin{array}{l}\text { Concept of getting well early by using antibiotics. } \\
\text { Thought the medicine was of poor quality in cases of antibiotic ineffectiveness. }\end{array}$ \\
\hline \multirow[t]{3}{*}{ Practices } & Use of antibiotics & $\begin{array}{l}\text { Use of antibiotics was inappropriate. } \\
\text { Purchase of antibiotics based on previous antibiotic prescriptions. } \\
\text { Use of home stock of antibiotics. } \\
\text { Mostly did not complete the duration of therapy. } \\
\text { Never followed the prescription strictly. } \\
\text { Never reported side effects occurring due to antibiotics. }\end{array}$ \\
\hline & $\begin{array}{l}\text { Consultation with } \\
\text { doctor }\end{array}$ & $\begin{array}{l}\text { Did not consult doctors until condition got worse. } \\
\text { Private sector doctors had high consultation fees. } \\
\text { Public sector doctors gave short consultation time. } \\
\text { Mostly did not follow the instructions given by the doctor. }\end{array}$ \\
\hline & $\begin{array}{l}\text { Consultation with } \\
\text { pharmacist }\end{array}$ & $\begin{array}{l}\text { Most of the pharmacies/medical stores did not have pharmacists. } \\
\text { Where community pharmacists are available, people did not ask questions due to lack of } \\
\text { awareness about the role of the pharmacist in healthcare system. }\end{array}$ \\
\hline \multirow{4}{*}{$\begin{array}{l}\text { Suggestions } \\
\text { for the } \\
\text { improvement } \\
\text { of healthcare } \\
\text { system }\end{array}$} & $\begin{array}{l}\text { General } \\
\text { population-related }\end{array}$ & $\begin{array}{l}\text { Patients should always consult the doctor for their illness. } \\
\text { Antibiotics should be used as prescribed by the doctor. }\end{array}$ \\
\hline & Doctor-related & Doctors should prescribe antibiotics based on conditions and avoid over-prescribing of antibiotics. \\
\hline & $\begin{array}{l}\text { Pharmacist- } \\
\text { related }\end{array}$ & $\begin{array}{l}\text { Availability of pharmacists at community pharmacies should be assured. } \\
\text { Out-dated prescriptions should not be refilled to minimize self-medication. }\end{array}$ \\
\hline & $\begin{array}{l}\text { Government- } \\
\text { related }\end{array}$ & $\begin{array}{l}\text { Improvements in the government hospital system to make this the preferred place to go. } \\
\text { Number of doctors should be increased so that doctors can give appropriate consultation time to } \\
\text { their patients. }\end{array}$ \\
\hline
\end{tabular}

Several respondents explained that diet was the major cause of antibiotic resistance as antibiotics are extensively used in poultry and vegetables are grown with contaminated water.

[...] It is very common that vegetables we use are grown with contaminated water which are the cause of hepatitis. Then there is spray of dangerous medicines on these vegetables so due to this how antibiotics can be effective. In poultry, antibiotics are used. Now all edible substances either it is vegetable or poultry of control shed or other contain these dangerous substances that lead to resistance [...] [Respondent A]

One respondent related the antibiotic resistance issue with the literacy rate as education will affect the health awareness too.

Foreigners are more familiar with research. They are educated more so this issue may be less in foreign countries. In Pakistan literacy rate is very low. (Respondent L)

\section{Theme 2:Attitude}

\section{Attitude regarding antibiotics}

Eleven respondents believed that antibiotics helped them to recover quicker from their illness so they preferred to use antibiotics. They also thought that antibiotics need to be used with other medicines to treat disease otherwise other medicines will not be effective. In this sense they are seen as an "add-on".

Antibiotics give instant effects. 1-2 tablets make the condition better so people prefer to use antibiotics... (Respondent B)

Because Brufen or Panadol alone just relieve the fever for time being. When the effect of medicine is ended, fever again... (Respondent $\mathrm{P}$ )

Some respondents stated that if antibiotics did not work they thought the medicine was of low quality.

...If it is not working it may be of low quality or of local company... (Respondent B) 


\section{Theme 3: practices Use of antibiotics}

Most respondents explained the history of previous ailments during their interview. Some of them had visited the physician for their past illness but the majority had not and purchased antibiotics from a pharmacy or medical store after telling their symptoms to a pharmacy "salesman" or by using the antibiotics left over from the previous prescription. Five of the respondents said that they used antibiotics based on their previous experience or upon the advice of a relative or friend.

From pharmacy we get without prescription. If we have severe problem then go to the doctor (Respondent F)

...If infection is similar to the previous one then I use the medicines of previous prescription... (Respondent L)

Sometimes we are suggested by a friend or relative to use an antibiotic for a condition they also had experienced (Respondent D)

The list of antibiotics most commonly purchased without prescription by the respondents for different ailments in Pakistan is provided in Supplementary material Table S11. Nine respondents stated that they used their home stocks of medicines, left over from previous illness. However, a minority of three respondents were of the opinion that leftover medicines should not be used and must be discarded.

Mostly we use without prescription. Most of the times, these are available at home as home stock, left from previous illness. (Respondent D)

...If medicine is left then we discard by removing it from its packs or flush it... (Respondent $\mathrm{O}$ )

Upon questioning regarding adherence to prescription instructions, 14 participants responded that instructions should be followed strictly.

Of course it should be followed strictly. Normally we take accordingly... (Respondent E)

However, some of the respondents thought that it was not necessary to follow the prescription strictly.

No, it should not be followed so strictly. Doctors forbid from everything... (Respondent D)

Some respondents said that the full course of therapy should be completed. They further stated that if the course of antibiotics is not completed, problems may occur.

...The days for which doctor has written, use and then leave.

... (Respondent F)
...Complete the course. Because bacteria can attack again, infection might recur, resistance may happen, if course is not completed... (Respondent $\mathrm{G}$ )

However, the majority of respondents were of the opinion that once they feel better, they could stop the therapy. According to these participants there is no problem with not completing the course and that continuing may lead to the side effects.

...If I get better earlier, then I can stop the therapy. If I will not stop then it can be overuse because problem is resolved now... (Respondent $\mathrm{J}$ )

According to two respondents, in the case of side effects they use symptomatic treatment and change their diet or sometimes reduce the dose to half to minimize the side effects. For example:

Loss of appetite I feel always. Then I skip the medicines or reduce the dose. By reducing the dose to half, side effects get better... (Respondent D)

\section{Consultation with doctors}

Only three respondents said that they always consult with a doctor for their minor ailments. They never undertake selfmedication, even for minor ailments.

Yes always consult with doctor. I never take medicines by myself. (Respondent C)

But the majority of participants do not always consult with a doctor. These folk use previous prescriptions of antibiotics when they have similar symptoms or they purchase antibiotics from a pharmacy or medical store, without a prescription. These respondents outlined multiple reasons for not consulting doctors, for example, financial problems, their busy schedule, distance from hospitals, overburdened government hospitals and the expensive consultation fees to see private physicians.

In Pakistan a poor man cannot even think as he is asked for the tests which are too expensive. At second, in outdoor clinics, there are too many patients and senior doctors do not come. For private clinics, Rs.1,500-2,000 is the fees so a poor person cannot afford that. He just thinks and go to government hospitals where there are too many patients. Doctors write medicines by hit and trials and write 2-4 medicines that any one of them will work. Doctors just want to get rid from patients in government hospitals; they give appropriate consultation when patients come at their private clinic. [Respondent A] 
...I usually take medicine by myself. Doctor is far away from my house. We live in a village. Doctor is far from village. Sometime person do not have time... (Respondent J)

\section{Consultation with pharmacists}

It would appear that for most respondents, community pharmacy is a new concept in Pakistan. Due to lack of awareness, people do not take health advice from pharmacists. There are few community pharmacies where pharmacists are available and people have built up their trust with pharmacy sales people who are not trained pharmacists. They generally ask these sales people all of their health-related questions.

No. I take medicines from workers at pharmacy. They are experienced and we had to take just one or two tablets. We trust them that they have experience so will give right medicine. There is no concept of pharmacist. We do not know that pharmacist can tell about medicines. [Respondent D]

No, here is no trend of pharmacist. People say that what doctor has written, would be right. All the questions are asked from the doctor. Pharmacists were not present at community pharmacies before so due to this reason here is no trend. [Respondent G]

No. here is no trend. No awareness regarding this topic. Awareness will increase as our education level will be increased. When people become aware of pharmacist, they go and ask about medicines from pharmacist. [Respondent L]

\section{Theme 3: suggestions for the improvement of the Pakistani healthcare system \\ General population-related}

Half of the respondents suggested that patients should always consult a doctor to ensure appropriate use of antibiotics. An example from respondent $\mathrm{G}$ :

...it is better to consult a doctor always otherwise do not use antibiotics... (Respondent G)

The respondents suggested that self-medication should not be undertaken and antibiotics should not be started on the basis of patients' previous personal experience with medicines.

...Go to the doctor and follow the prescription. Do not self-medicate... (Respondent $\mathrm{H}$ )

Rural residents suggested that appropriate healthcare facilities should be provided in villages where the literacy rate is low and patients are not aware of what approach should be taken in the case of illness.

$50 \%$ of general public of Pakistan is illiterate, living in villages. These people do not have facilities that they can access the health care professionals. Government should take measures $[\ldots]$ [Respondent $\mathrm{L}]$

\section{Physician-related}

A majority of respondents suggested that doctors should prescribe antibiotics according to their diagnosis based on the patients' condition and they should not prescribe antibiotics if not needed. Doctors should guide the patients properly and help them to understand the proper use of antibiotics. Doctors should provide appropriate consultation time to their patients.

Doctor should prescribe according to patient's condition...

(Respondent A)

Doctor should check the patient very carefully. Make him understand that what are the benefits of taking antibiotics and what are the hazards. Give them appropriate time (Respondent I)

Respondents were of the opinion that doctors should not prescribe unnecessary antibiotics and should prescribe multinational brands which are obtainable from all pharmacies and medical stores. The idea that doctors receive incentives to prescribe did not sit well with some participants.

[...] Doctors have started writing antibiotics much more.

They take money from medical representatives and start writing. Some doctors have their own pharmacies. It should be stopped [...]. [Respondent E]

\section{Pharmacist-related}

Unfortunately, only two of the 16 participants knew what the role of the community pharmacist involved; particularly around the provision of medical advice. The remainder of the participants did not know that a Pakistani pharmacist is a qualified person who can offer sound advice and educate them about the optimal use of medicines. However, upon explaining the role of the community pharmacist to these participants (Supplementary material Box S12), they agreed that the pharmacist should be present at pharmacies for patient counseling.

Pharmacists should be in surrounding to the doctor. If pharmacists will be available, they will guide better... (Respondent O)

...Pharmacist availability should be assured for full time at all drug stores... (Respondent $\mathrm{K}$ ) 
Two respondents stated that pharmacies and medical stores should clearly display that pharmacists are available for patient counseling.

...Pharmacies should display that pharmacist is available here and these are the purposes and duties of pharmacist. You can take advice from them about your medicines... (Respondent O)

According to eight respondents, Pakistani pharmacists should provide advice and guide patients about the appropriate use of antibiotics. Here is an example from respondent G:

...Pharmacist should guide the patients that for how many days you have to take this medicine and many other things as side effects etc. These should be told... (Respondent G)

\section{Government-related}

Two respondents stated that the government should take measures to improve the system within government-funded hospitals so that patients prefer to go to the government hospitals rather than private clinics. They further stated that public sector doctors should not be allowed to undertake private practice activities in the evening.

If in government hospitals, right treatment is started then all the misuse of medicines will be ended. Doctors practicing private, they should be just private and government doctors should just practice in government hospitals. It can solve the problem because if private sector doctors check on private clinics and government sector doctors will not check other than government hospital then it all will be fine. In this way patient load will be divided. (Respondent D)

One respondent suggested that the date on prescriptions should be checked at the time of filling, as this will minimize the chance of self-medication. The participant also emphasized that outdated prescriptions should not be filled.

Government should implement that if a person goes to the pharmacy or a medical store then the pharmacist should check the date on the prescription. Prescriptions without date or of previous dates should not be fulfilled for all drugs. (Respondent $\mathrm{O}$ )

The inappropriate use of antibiotics in Pakistan is driven by a series of complex factors and a summary of these is outlined in the table below (Table 8).

\section{Discussion}

This is the first mixed-methods study conducted in Pakistani community pharmacy to explore the general public's knowledge, attitude and behavior toward antibiotic use. This study also reports the perceptions linked to the inappropriate use of antibiotics. The study found that participants' knowledge about antibiotics was at a moderate level whilst their attitude towards appropriate antibiotic use was poor. The more common poor behaviors include lack of consultation with

Table 8 Summary of results

\begin{tabular}{|l|}
\hline What drives inappropriate use of antibiotics? \\
\hline Quantitative \\
\hline Knowledge of antibiotics among general public was moderate in nature. \\
\hline Attitude of general public regarding the use of antibiotics was poor. \\
\hline Dosage regimen of antibiotics was not appropriate. \\
\hline Patients ceased antibiotic courses when they felt better, regardless of whether they had completed the course. \\
\hline Education level and urban residency were significantly associated with antibiotic knowledge. \\
\hline $\begin{array}{l}\text { Antibiotics purchased without a prescription, knowledge score about antibiotics and male gender were the main determinants of attitudes toward } \\
\text { antibiotic use. }\end{array}$ \\
\hline Qualitative \\
\hline Familiar with the term "antibiotic" but low knowledge of the medical conditions that can be treated with antibiotics. \\
\hline Had insufficient knowledge about antibiotic resistance. \\
\hline $\begin{array}{l}\text { Inappropriate use of antibiotics included; lack of consultation with healthcare professionals, purchase of antibiotics without a prescription or with a } \\
\text { previous prescription, use of home stock of antibiotics, sharing of antibiotic prescriptions with others and improper dosage regimen. }\end{array}$ \\
\hline $\begin{array}{l}\text { Low health literacy, high consultation fees of private practitioners, inadequate health facilities in government hospitals and patient overload, busy } \\
\text { schedule of people, poor healthcare infrastructure in rural areas and unrestricted supply of antibiotics were the key factors associated with the } \\
\text { inappropriate use of antibiotics. }\end{array}$ \\
\hline It is expected that doctors would prescribe antibiotics according to condition and avoid over-prescribing of antibiotics. \\
\hline Availability of a pharmacist at community pharmacies should be assured. \\
\hline Out-dated prescriptions should not be refilled to minimize self-medication. \\
\hline Improvement in government sector hospitals was suggested. \\
\hline
\end{tabular}


healthcare professionals, purchase of antibiotics without a prescription or refilling of previous prescriptions, use of home stock of antibiotics, sharing of antibiotic prescriptions with others, taking improper dosage regimens and termination of antibiotic therapy before completing the whole course. People used antibiotics more than their needs and also for those conditions which did not require antibiotics. Most of the respondents did not know their average consumption of antibiotics per year.

One of the startling findings was the perception that all conditions can be treated with antibiotics. Most of the respondents were unable to distinguish between bacterial and viral infections, which will have an impact on more frequent use of antibiotics for influenza-like symptoms, coughs, colds and fever. Similar findings have been reported in the UK and Pakistan where $46 \%$ and $39 \%$ of participants, respectively, thought that antibiotics could be used to treat viral infections. ${ }^{17,34}$ A Lebanese study also revealed that nearly three-quarters $(73.5 \%)$ of the sampled population used antibiotics for all conditions whether bacterial or viral. ${ }^{4}$ The possible reason could be the use of a general term "germs", in medical counseling instead of the terms "virus" or "bacteria". Additionally, patients are not well trained to tell the difference and doctors often prescribe antibiotics for influenza or coughs and colds to manage patient expectations and perceived quicker recovery. In the present study, people were unaware of the term "antibiotic resistance". Similar results were shown in a survey conducted in Jordan where $60.7 \%$ of respondents had poor knowledge about antibiotic resistance. ${ }^{35}$ Another noteworthy finding of the current study was that the majority of the people thought they could discontinue the course when they felt better. In this study course completion was defined as the prescribed regimen being consumed appropriately for a specific period of time. ${ }^{36}$ A Serbian study also reported that nearly half (43\%) of the respondents believed that antibiotics could be stopped when symptoms ceased. ${ }^{37}$ The reason may be the misconception that antibiotics are equivalent to antipyretics, analgesics or anti-inflammatories.

In the quantitative component of this study, the results of multiple linear regression analysis demonstrated that knowledge of antibiotics was directly associated with education level. Respondents who were illiterate or had only primary school education had poor levels of knowledge. These findings are comparable with studies from Italy, UK, Hong Kong, Sweden, Lithuania, Poland and Cyprus, where respondents with lower education had low health literacy. ${ }^{26,38,39}$ A Serbian study also showed that about half $(47.8 \%)$ of the respondents with lower levels of education had inadequate knowledge about antibiotics. ${ }^{37}$ This appears to be a cross-cultural phenomenon.

Besides superficial knowledge about antibiotics, poor attitude toward antibiotic use was observed among half of the respondents, which aligns with a Serbian study where $47.2 \%$ of the respondents demonstrated inappropriate attitudes toward antibiotic use. ${ }^{37}$ The findings of our study show that participants who consulted a doctor during a time of illness expected the doctor to prescribe them antibiotics for the common cold. The underlying reason may be that the patients believed that "germs are germs". They had little understanding of the different causes of infection. They viewed viruses and bacteria together as "germs" and made no distinction. Findings from our study also indicated that participants preferred to keep leftover antibiotics at home for future use. This is a global issue and our study aligns with those conducted in China and Jordan where 31\% and $49 \%$ of participants, respectively, consume leftover antibiotics from previous infections. ${ }^{5,35}$ This might be due to the natural inclination to keep something that can be useful later on; specifically, if it involves inconvenience or expense as is the case with antibiotics in Pakistan. Patients may think if a medicine worked for a purpose previously, it might do so again. Our study found that half of the respondents took antibiotics from relatives and friends. A similar situation was noted in a Jordanian study in which half (51.8\%) of study participants used antibiotics based on a relative's advice. ${ }^{35}$ In this study almost half of the respondents thought it was right to buy the same antibiotics if symptoms were the same as before and again this aligns with international consumer behavior in Nigeria (56\%), India (52\%), Egypt (51\%) and Indonesia $(51 \%) .{ }^{37}$

The multivariate analysis demonstrated that the knowledge about antibiotics was directly related to the attitude of the general public regarding antibiotic use. This relationship has already been demonstrated in a previous study where respondents with adequate antibiotic knowledge were more likely to report appropriate attitude with regard to antibiotic use. ${ }^{37}$ The present study also revealed that people who purchased more antibiotics without a prescription had poor attitudes. This association is supported by an Italian study where $32.7 \%$ of the study population were more likely to undertake self-medication since they had taken antibiotics without prescriptions during past years. ${ }^{38}$

Despite the fact that respondents in our study claimed that they purchase antibiotics with a doctor's prescription, the majority used prescriptions from previous illnesses with 
similar symptoms. The dosage regimen was not appropriate as people purchased only one or two doses of antibiotics as the prices of antibiotics are high. A Lebanese study showed similar findings where nearly two-thirds (65.1\%) of the respondents took antibiotics with a doctor's prescription, but the dosage regimen was not appropriate, ${ }^{4}$ with one reason being the poor financial status of the respondents. In our study, some participants also reported self-medication of antibiotics and incomplete courses of treatment. These findings were comparable to a previous study whereby just over one-third (35\%) of the population consumed antibiotics without a prescription and over one-fifth $(22.4 \%)$ chose to take antibiotics of their own accord. ${ }^{4}$ Interestingly, self-medication has also been reported in some European countries (19.8\% in Romania, $15.2 \%$ in Spain, and $21 \%$ in Lithuania).${ }^{14} \mathrm{~A}$ low level of knowledge, sub-optimal healthcare facilities and an unrestricted supply of antibiotics available without a prescription are likely reasons contributing to the self-medication of antibiotics in the present study.

The purchase of antibiotics without a prescription was also common amongst the cohort in the present study. Although the existing regulations do not allow antibiotics to be dispensed without a prescription in Pakistan, unfortunately these rules are not implemented, which allows the sale of antibiotics without a prescription. This reflects the situation in Syria, India and Spain. ${ }^{40-42}$ The Syrian study found an alarming percentage $(89.3 \%)$ of antibiotics being sold without a prescription. ${ }^{40}$ Sharing the prescription with others having the same infections due to lack of patient details was also very common in our study. Ignoring the need for date and patient details on the prescription at the time of dispensing of the antibiotics allows easy sharing of antibiotic prescriptions. Similar findings were shown in a previous study whereby 78 adults out of 200 (39\%) refilled the same prescription for the illness they experienced in the past, whereas 51 adults $(25.5 \%)$ shared their prescription with others. ${ }^{43,44}$

There is no doubt that knowledge about antibiotics is complex and the findings from this study have wider implications for the Pakistani health system and the population as a whole. Promoting education as an isolated measure is unlikely to improve antibiotic use to a point where antimicrobial resistance will decline to any great extent. There are wider economic, political and societal contextual factors that come into play, and these warrant consideration. Clearly, general education levels of the population play a significant role and so any campaigns to be instituted will need to be designed to be understood by a largely illiterate population. Lack of affordable (or any) healthcare that could regulate and control antibiotic use, and the economic interests of doctors and pharmacists may also contradict appropriate antibiotic usage. Regulatory change needs to occur at the policy maker level and so it is hoped that this study helps to make regulators aware of the issues. The fiscal interests of doctors and pharmacists requires a shift in professional culture and academic institutions, professional associations and regulatory disincentives will play an important role in shifting this mind set. Of course, all these issues need to be tackled simultaneously to achieve sustainable improvement in reducing antimicrobial resistance.

\section{Limitations}

This study has several limitations. The use of convenience sampling techniques means that only respondents having an interest in the topic area may have volunteered to participate in the study. Others may have different views. Another limitation is that females were under-represented in the qualitative phase of the study due to the cultural context in Pakistan, as females hesitate to give detailed interviews. Similarly, our findings cannot not be generalized to the whole of Pakistan; but these findings give an indication of what is happening in one city. Based on the fact that a uniform healthcare policy is implemented throughout the country, and people from different areas are working in Bahawalpur, attitudes and behavior towards antibiotics are expected to be similar to other cities in Pakistan. Limited time span to recruit respondents was also a limitation. We also did not control familywise error rate across the reported statistical tests which is another limitation of this study. Implications for future research include the need for longitudinal and interventional studies to better understand people's perception of antibiotic-related issues over time and to devise better systems to change behaviors and minimize the global threat of antibiotic resistance due to misuse.

\section{Conclusion}

This mixed-methods study set out to understand attitudes and behavior towards the use of antibiotics with respondents presenting at two community pharmacies in one city in Pakistan. The participants had a moderate level of knowledge but poor attitudes towards the use of antibiotics. Being illiterate and having primary level of education were significant predictors of knowledge about antibiotics. Similarly, male gender, purchase of antibiotics without a prescription and knowledge about antibiotics were significant predictors of attitude towards antibiotic use. Common behaviors included: use of inappropriate dosage regimens, sharing of prescriptions with 
others, refilling antibiotic prescriptions and not completing courses when improvements were seen. Level of education, low health literacy, high consultation fees of private practitioners, inadequate health facilities and patient overload in government hospitals, busy schedule of people, poor healthcare infrastructure in rural areas and unrestricted supply of antibiotics were key factors associated with inappropriate use of antibiotics in the city of Bahawalpur, Pakistan.

\section{Implications of the findings}

This study has some notable implications for policy and practice. The findings suggest a dire need for campaigns to improve general public awareness and understanding of the problem of antibiotic misuse. On the policy front, implementation of global communication programs is required. Immediate strategies are necessary to minimize the sale of antibiotics without prescription in developing nations such as Pakistan, so as to reduce the risk of antibiotic resistance and mortality rate due to resistant infections. A national pharmaceutical policy is needed to be developed in Pakistan to address this issue.

\section{Acknowledgments}

We would like to thank the respondents for their participation in this study. This research did not receive any specific grant from funding agencies in the public, commercial or not-for-profit sectors.

\section{Author contributions}

All authors contributed to data analysis, drafting and revising the article, gave final approval of the version to be published, and agree to be accountable for all aspects of the work.

\section{Disclosure}

The authors report no conflicts of interest in this work

\section{References}

1. Almeida Santimano NM, Foxcroft DR. Poor health knowledge and behaviour is a risk for the spread of antibiotic resistance: survey of higher secondary school students in Goa, India. Perspect Public Health. 2017;137(2):109-113.

2. Harbarth S, Balkhy HH, Goossens H, Jarlier V, Kluytmans J. Antimicrobial resistance: one world, one fight! Antimicrob Resist Infect Control. 2015;4:49.

3. Centers for disease control and prevention, United States: Antibiotic/ Antimicrobial Resistance (AR/AMR); 2018. Available from: https:// www.cdc.gov/drugresistance/index.html. Accessed November 01, 2018.

4. Mouhieddine TH, Olleik Z, Itani MM, et al. Assessing the Lebanese population for their knowledge, attitudes and practices of antibiotic usage. J Infect Public Health. 2015;8(1):20-31.

5. Ye D, Chang J, Yang C, et al. How does the general public view antibiotic use in China? Result from a cross-sectional survey. Int J Clin Pharm. 2017;39(4):927-934.
6. Rajalingam B, Susan Alex A, Godwin A, Cherian C, Cyriac C. Assessment of rational use of antibiotics in a private tertiary care teaching hospital. Indian J Pharm Pract. 2016;9(1):14-18.

7. Salim AM, Elgizoli B. Exploring the reasons why pharmacists dispense antibiotics without prescriptions in Khartoum state, Sudan. Int J Pharm Pract. 2017;25(1):59-65.

8. Costelloe C, Metcalfe C, Lovering A, Mant D, Hay AD. Effect of antibiotic prescribing in primary care on antimicrobial resistance in individual patients: systematic review and meta-analysis. BMJ. 2010;340:c2096.

9. Lum EPM, Page K, Nissen L, Doust J, Graves N. Australian consumer perspectives, attitudes and behaviours on antibiotic use and antibiotic resistance: a qualitative study with implications for public health policy and practice. BMC Public Health. 2017;17(1):799.

10. Piltcher OB, Kosugi EM, Sakano E, et al. How to avoid the inappropriate use of antibiotics in upper respiratory tract infections? A position statement from an expert panel. Braz J Otorhinolaryngol. 2018;84(3):265-279.

11. Vazquez-Lago J, Gonzalez-Gonzalez C, Zapata-Cachafeiro M, et al. Knowledge, attitudes, perceptions and habits towards antibiotics dispensed without medical prescription: a qualitative study of Spanish pharmacists. BMJ Open. 2017;7(10):e015674.

12. Bryce A, Costelloe C, Wootton M, Butler CC, Hay AD. Comparison of risk factors for, and prevalence of, antibiotic resistance in contaminating and pathogenic urinary Escherichia coli in children in primary care: prospective cohort study. J Antimicrob Chemother. 2018;73(5):1359-1367.

13. O'Neill J. Tackling Drug-Resistant Infections Globally: Final Report and Recommendations. 2016. UK: HM Government and Welcome Trust; 2018.

14. Al-Azzam SI, Al-Husein BA, Alzoubi F, Masadeh MM, Al-Horani MA. Self-medication with antibiotics in Jordanian population. Int J Occup Med Environ Health. 2007;20(4):373-380.

15. Atif M, Azeem M, Sarwar MR, et al. WHO/INRUD prescribing indicators and prescribing trends of antibiotics in the Accident and Emergency Department of Bahawal Victoria Hospital, Pakistan. Springerplus. 2016;5(1):1928.

16. Essack S, Bell J, Shephard A. Community pharmacists-Leaders for antibiotic stewardship in respiratory tract infection. J Clin Pharm Ther. 2018;43(2):302-307.

17. Mason T, Trochez C, Thomas R, et al. Knowledge and awareness of the general public and perception of pharmacists about antibiotic resistance. BMC Public Health. 2018;18(1):711.

18. Atif M, Azeem M, Saqib A, Scahill S. Investigation of antimicrobial use at a tertiary care hospital in Southern Punjab, Pakistan using WHO methodology. Antimicrob Resist Infect Control. 2017;6(1):41.

19. Morgan DJ, Okeke IN, Laxminarayan R, Perencevich EN, Weisenberg $\mathrm{S}$. Non-prescription antimicrobial use worldwide: a systematic review. Lancet Infect Dis. 2011;11(9):692-701.

20. Hussain T. Pakistan at the verge of potential epidemics by multi-drug resistant pathogenic bacteria. Adv Life Sci. 2015;2(2):46-47.

21. Ashraf F, Hafeez A, Imtiaz F, Ayub A, Imtiaz H. Antibiotic dispensing and prescription pattern in pharmacies of Islamabad and Rawalpindi: Pakistan. Int J Collaborative Res Intern Med Public Health. 2017;9(5):683-692.

22. Klein EY, van Boeckel TP, Martinez EM, et al. Global increase and geographic convergence in antibiotic consumption between 2000 and 2015. Proc Natl Acad Sci USA. 2018;115(15):E3463-E3470.

23. Atif M, Azeem M, Rehan Sarwar M, et al. Evaluation of prescription errors and prescribing indicators in the private practices in Bahawalpur, Pakistan. J Chin Med Assoc. 2018;81(5):444-449.

24. Atif M, Sarwar MR, Azeem M, et al. Assessment of core drug use indicators using WHO/INRUD methodology at primary healthcare centers in Bahawalpur, Pakistan. BMC Health Serv Res. 2016;16(1):684.

25. Faizullah M, Rahman N, Umar MI, Anwar M, Sarfraz M. A crosssectional study on knowledge, attitude and practices of medical doctors towards antibiotic prescribing patterns and resistance in Khyber Pakhtun Khawah, Pakistan. J Appl Pharm Sci. 2017;7(12):38-46.

26. McNulty CAM, Boyle P, Nichols T, Clappison P, Davey P. Don't wear me out-the public's knowledge of and attitudes to antibiotic use. $J$ Antimicrob Chemother. 2007;59(4):727-738. 
27. Pakistan Bureau of Statistics, PBS: Population Census; 2017. Available from: www.pbs.gov.pk/content/population-census. Accessed November 01,2018

28. Sample Size Calculator by Raosoft, 2004. Available from: www.raosoft. com/samplesize.html. Accessed November 01, 2018.

29. Atif M, Javaid S, Farooqui M, Sarwar MR. Rights and responsibilities of tuberculosis patients, and the global fund: a qualitative study. PLoS One. 2016;11(3):e0151321.

30. Gjersing L, Caplehorn JR, Clausen T. Cross-cultural adaptation of research instruments: language, setting, time and statistical considerations. BMC Med Res Methodol. 2010;10(1):13.

31. Tsang S, Royse C, Terkawi A. Guidelines for developing, translating, and validating a questionnaire in perioperative and pain medicine. Saudi J Anaesth. 2017;11(5):80.

32. Field A. Discovering Statistics Using IBM SPSS Statistics. Thousand Oaks: Sage; 2013.

33. Saqib A, Atif M, Ikram R, et al. Factors affecting patients' knowledge about dispensed medicines: A Qualitative study of healthcare professionals and patients in Pakistan. PLoS One. 2018;13(6):e0197482.

34. Sarwar M, Saqib A, Iftikhar S, Sadiq T. Knowledge of community pharmacists about antibiotics, and their perceptions and practices regarding antimicrobial stewardship: a cross-sectional study in Punjab, Pakistan. Infect Drug Resist. 2018;11:133-145.

35. Shehadeh M, Suaifan G, Darwish RM, et al. Knowledge, attitudes and behavior regarding antibiotics use and misuse among adults in the community of Jordan. A pilot study. Saudi Pharm J. 2012;20(2):125-133.

36. World Health Organization, WHO: Does stopping a course of antibiotics early lead to antibiotic resistance? 2017. Available from: https:// www.who.int/features/qa/stopping-antibiotic-treatment/en/. Accessed November 01, 2018.
37. Horvat OJ, Tomas AD, Paut Kusturica MM, et al. Is the level of knowledge a predictor of rational antibiotic use in Serbia? PLoS One. 2017;12(7):e0180799.

38. Napolitano F, Izzo MT, Di Giuseppe G, Angelillo IF. Public knowledge, attitudes, and experience regarding the use of antibiotics in Italy. PLoS One. 2013;8(12):e84177.

39. World Health Organization, WHO: Antibiotic resistance: Multi-country public awareness survey; 2015. Available from: https:/www.who. int/drugresistance/documents/baselinesurveynov2015/en/. Accessed November 01, 2018.

40. Bahnassi A. A qualitative analysis of pharmacists' attitudes and practices regarding the sale of antibiotics without prescription in Syria. J Taibah Univ Med Sci. 2015;10(2):227-233.

41. Shet A, Sundaresan S, Forsberg BC. Pharmacy-based dispensing of antimicrobial agents without prescription in India: appropriateness and cost burden in the private sector. Antimicrob Resist Infect Control. 2015;4(1):55.

42. Zapata-Cachafeiro M, González-González C, Váquez-Lago JM, et al. Determinants of antibiotic dispensing without a medical prescription: a cross-sectional study in the north of Spain. JAntimicrob Chemother. 2014;69(11):3156-3160.

43. Arshad S, Mahmood S, Rasool S, et al. Rational Drug use in Pakistan: A systematic review. J Pharm Pract Community Med. 2016;2(4):116-122.

44. Hameed A, Naveed S, Qamar F, Alam T, Abbas SS, Sharif N. Irrational use of antibiotics. Different Age Groups of Karachi: a wakeup call for antibiotic resistance and future infections. J Bioequiv Availab. 2016;8:242-245.

45. Joint Formulary Committee, British National Formulary. Vol 67. London, BMJ Group and Pharmaceutical Press; 2014.
Infection and Drug Resistance

\section{Publish your work in this journal}

Infection and Drug Resistance is an international, peer-reviewed openaccess journal that focuses on the optimal treatment of infection (bacterial, fungal and viral) and the development and institution of preventive strategies to minimize the development and spread of resistance. The journal is specifically concerned with the epidemiology of antibiotic

\section{Dovepress}

resistance and the mechanisms of resistance development and diffusion in both hospitals and the community. The manuscript management system is completely online and includes a very quick and fair peerreview system, which is all easy to use. Visit http://www.dovepress.com/ testimonials.php to read real quotes from published authors. 